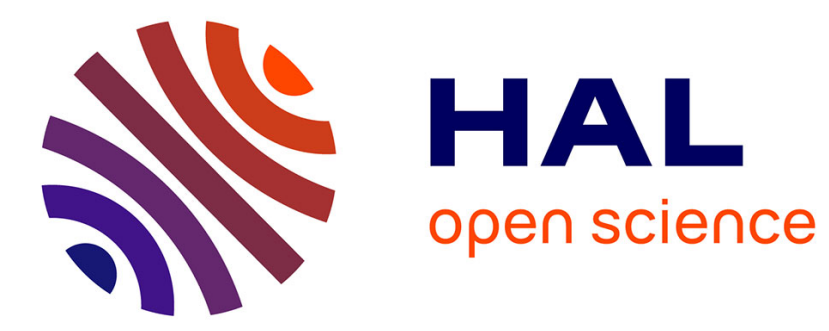

\title{
Strong improvement in the photonic stop-band edge sharpness of a lithium niobate photonic crystal slab
}

S. Diziain, S. Harada, R. Salut, P. Muralt, M.-P. Bernal

\section{To cite this version:}

S. Diziain, S. Harada, R. Salut, P. Muralt, M.-P. Bernal. Strong improvement in the photonic stopband edge sharpness of a lithium niobate photonic crystal slab. Applied Physics Letters, 2009, 95 (10), pp.101103. 10.1063/1.3223595 . hal-00414690

\section{HAL Id: hal-00414690 \\ https://hal.science/hal-00414690}

Submitted on 3 May 2021

HAL is a multi-disciplinary open access archive for the deposit and dissemination of scientific research documents, whether they are published or not. The documents may come from teaching and research institutions in France or abroad, or from public or private research centers.
L'archive ouverte pluridisciplinaire HAL, est destinée au dépôt et à la diffusion de documents scientifiques de niveau recherche, publiés ou non, émanant des établissements d'enseignement et de recherche français ou étrangers, des laboratoires publics ou privés. 


\title{
Strong improvement in the photonic stop-band edge sharpness of a lithium niobate photonic crystal slab
}

\author{
S. Diziain, ${ }^{1, a)}$ S. Harada, ${ }^{2}$ R. Salut, ${ }^{1}$ P. Muralt, ${ }^{2}$ and M.-P. Bernal ${ }^{1}$ \\ ${ }^{1}$ Département d'Optique, Institut FEMTO-ST, CNRS UMR6174, Université de Franche-Comté, \\ 16 route de Gray, 25030 Besançon Cedex, France \\ ${ }^{2}$ Ceramics Laboratory, EPFL, MXD station 12, CH-1015 Lausanne, Switzerland
}

(Received 19 May 2009; accepted 17 August 2009; published online 8 September 2009)

\begin{abstract}
We report on a photonic crystal $(\mathrm{PhC})$ etched into a $380 \mathrm{~nm}$ thick lithium niobate (LN) thin film deposited on a $\mathrm{MgO}$ substrate by pulsed laser deposition. The transmission properties of this device were assessed by optical near-field measurements and compared to the transmission spectra of the same $\mathrm{PhC}$ drilled into bulk LN and calculated by a two dimensional finite-difference time domain method. We show a strong improvement in the transmission properties of the LN PhC by etching it into a thin layer rather than into a $500 \mu \mathrm{m}$ thick wafer. This result appears to be very promising for applications based on LN tunable PhCs. (C) 2009 American Institute of Physics.
\end{abstract}

[doi:10.1063/1.3223595]

Photonic crystals (PhCs) are optical nanostructures, for which the periodic variations of the dielectric function are designed to control the light propagation for specific applications. ${ }^{1} \mathrm{PhCs}$ fabricated with active materials offer the ability to tune their properties in a flexible way, without changing the design of the device. Among the variety of active materials, lithium niobate (LN), which combines high Curie temperature with high refractive index and large optical nonlinearities, has proven to be a good candidate for two-dimensional (2D) tunable PhC devices. ${ }^{2-4}$ These PhCs, developed mainly for integrated optics applications in the $1.55 \mu \mathrm{m}$ wavelength range, were manufactured by milling nanometric size air holes by focused ion beam (FIB) (Ref. 5) on the surface of a $500 \mu \mathrm{m}$ thick $X$-cut LN wafer, on which an optical index gradient waveguide was fabricated by annealed proton exchange (APE). ${ }^{6}$ The high resistivity of LN and the material redeposition during the etching process are responsible for the finite depth and the conical shape of the holes, which limits the overlap between the shallow $\mathrm{PhC}$ and the buried guided mode, and degrades the capacities of the devices. ${ }^{7}$ Given the difficulty of milling high aspect-ratio cylindrical nanoholes in LN, a solution consists in etching PhCs into a LN layer with a thickness of only several hundreds of nanometers. Nevertheless, the critical issue lies in depositing LN thin films with crystalline and optical properties comparable to those of the bulk material. Such kind of layers can be obtained by the crystal ion slicing technique. ${ }^{8,9}$ This technique requires expensive high energy ion implantation engineering, which is not suitable for routine applications. To overcome this drawback, some alternative methods based on epitaxial growth, such as metalorganic chemical vapor deposition and pulsed laser deposition (PLD), are currently in progress. 10,11

In this letter, we show the first realization of a $2 \mathrm{D} \mathrm{PhC}$ etched into a $380 \mathrm{~nm}$ thick $\mathrm{LN}$ film deposited on a $\mathrm{MgO}$ substrate by a PLD technique. Our goal is to use this method to grow single crystal films of $\mathrm{LN}$ with the $c$-axis oriented

\footnotetext{
a)Present address: Center for Innovation Competence "ultra optics," Institute of Applied Physics, Friedrich-Schiller-Universität Jena, Max Wien Platz 1, 07743 Jena, Germany. Electronic mail: severine.diziain@uni-jena.de.
}

perpendicular to the substrate. The $\mathrm{MgO}$ substrate was chosen because its refractive index is lower than the one of $\mathrm{LN},{ }^{12}$ so that the proposed structure acts as a slab waveguide. In order to show the advantage of milling holes into thin layers rather than into bulk $\mathrm{LN}$, a $\mathrm{PhC}$ was etched into the LN film, using the same design as for the earlier version obtained from bulk crystalline LN., ${ }^{3,4}$ The transmission spectrum of this structure was measured by scanning near-field optical microscopy (SNOM) and compared first to the transmission spectrum of the PhC etched in bulk $\mathrm{LN}^{3,4}$ and then to the transmission spectrum calculated by a finite-difference time domain (FDTD) method.

The $\mathrm{LiNbO}_{3}$ film was deposited using a custom built PLD chamber in combination with a Lambda Physik excimer laser $(\lambda=193 \mathrm{~nm})$. The laser fluence, calculated from the beam spot size, was $1.3 \mathrm{~J} \cdot \mathrm{cm}^{-2}$ and the repetition rate $A$ polished, $\mathrm{MgO}$ (100) single crystal, heated to $650{ }^{\circ} \mathrm{C}$ in an $\mathrm{O}_{2}$ atmosphere $(0.1 \mathrm{mbar})$, was used as the substrate for the film. The deposition was conducted for $15 \mathrm{~min}$, which resulted in a film thickness of approximately $380 \mathrm{~nm}$. X-ray diffraction (XRD) analysis showed the film grew with a (101) preferred orientation (Fig. 1).

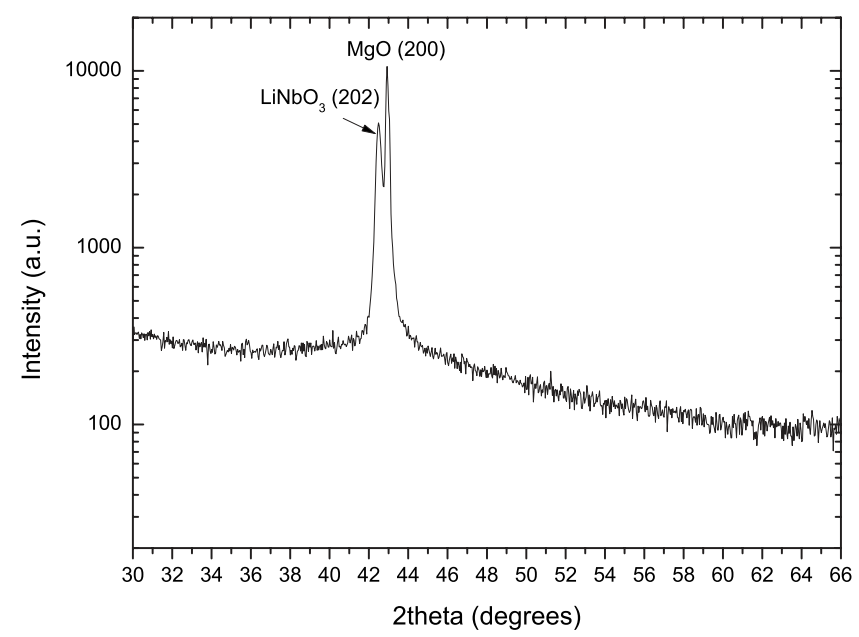

FIG. 1. XRD data for the $\mathrm{LiNbO}_{3}$ film deposited onto an $\mathrm{MgO}$ (100) single crystal substrate. 


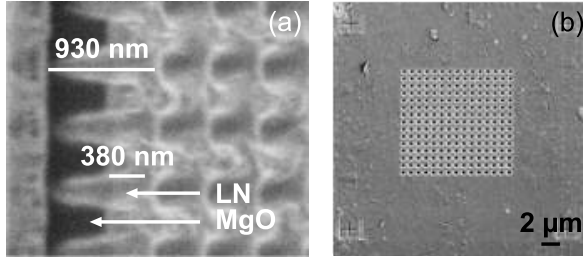

FIG. 2. (a) SEM image of the hole profiles into a LN thin film deposited on a MgO substrate by PLD. The FIB cross section exhibits the hole size and shape and the thickness of the LN layer. (b) SEM image of the PhC.

This thin LN film, despite its polycrystallinity, offered the capability to vertically confine the light. Although losses were not quantified because it was not the goal of this letter, this slab waveguide appears to be suitable for integrated devices based on PhCs. The PhC, consisting of a square lattice of $15 \times 15$ holes with $207 \mathrm{~nm}$ radius and $766 \mathrm{~nm}$ periodicity, was etched by FIB implantation. Gallium ions emitted with a current of $2 \mu \mathrm{A}$ and accelerated by a voltage of $30 \mathrm{kV}$ were focused on the surface of the LN thin film. To minimize redeposition effects responsible for the conical shape of the holes, a multipass type raster scan with seven loops was used. With such FIB parameters, the etching depth is equal to $930 \mathrm{~nm}$, so that both the LN thin film and the substrate were milled, resulting in an almost vertical sidewall of the air-hole part etched into the LN layer. The shape of the holes and the scanning electron microscopy (SEM) image of the $\mathrm{PhC}$ are shown in Figs. 2(a) and 2(b), respectively.

In this planar waveguide, the light is not laterally confined, so that the light beam scattered by the $\mathrm{PhC}$ diverges in the horizontal plane. Moreover, the output facet of the sample was not polished giving rise to a huge scattering and making the detection of the optical signal coming from the $\mathrm{PhC}$ impossible by classical far-field transmission measurements. A solution for extracting the optical response of the $\mathrm{PhC}$ from this background and for measuring the transmission spectrum was to use optical near-field experiments. A monochromatic light coming from a tunable laser was injected into the LN thin layer. The laser beam was polarized perpendicularly to the hole axis (TE-polarization). For SNOM image recordings, a dielectric tip, collecting the evanescent waves, scanned a planar waveguide surface of 30 $\times 30 \mu \mathrm{m}^{2}$ centered around the $\mathrm{PhC}$. The nanometric distance between the SNOM probe and the sample surface was maintained constant during the scan by a shear-force regulation. Simultaneously with the optical near-field image, the shear-force image was recorded, giving a topography information. Figure 3(a) shows an example of the scanning zone. For spectroscopic analyses, several SNOM images were acquired, each one with a specific wavelength. Since the recording of each SNOM image lasted for at least 21 min, only a limited number of interesting wavelengths were selected. Figure 3(b) shows two examples of horizontal cross-sections plotted at the center position of the $\mathrm{PhC}$ above the optical near-field images acquired at 1520 and $1600 \mathrm{~nm}$, respectively. On these curves, it appears that the propagation of the incident light does not depend on the wavelength before getting through the $\mathrm{PhC}$ (abscissa ranging between 30 and $20 \mu \mathrm{m}$ ) but, after the propagation through the PhC (abscissa ranging between 9.5 and $0 \mu \mathrm{m}$ ), the optical signal strongly depends on the wavelength. In the near proximity of the PhC $(\sim 7$ or $8 \mu \mathrm{m})$, the optical near-field undergoes strong variations due to the presence of the $\mathrm{PhC}$, while, outside this zone, the optical near-field signal keeps almost constant during its propagation inside the slab. Thus, for each wavelength, the normalized intensity transmitted through the $\mathrm{PhC}$ was deduced by dividing the optical near-field intensity measured at $9 \mu \mathrm{m}$ from the $\mathrm{PhC}$ output [abscissa equal to $0.5 \mu \mathrm{m}$ on Fig. 3(b)] by the optical near-field intensity measured at $9 \mu \mathrm{m}$ before the $\mathrm{PhC}$ entrance [abscissa equal to $29 \mu \mathrm{m}$ on Fig. 3(b)]. These abscissa were chosen because they correspond to positions for which the $\mathrm{PhC}$ does not influence the propagation of the light. For each optical nearfield image (and thus wavelength), several parallel horizontal cross sections were plotted along the $\mathrm{PhC}$ and the previously method was applied to each curve in order to determine the normalized transmission. The experimental transmission spectrum reported in Fig. 4 for wavelengths ranging from 1520 to $1620 \mathrm{~nm}$ arises from the average of all these measurements and the error bars represent the standard deviation of these measurements.

This spectrum exhibits a stop band characterized by a mean transmission of $35 \%$ from $1520 \mathrm{~nm}$ up to $1585 \mathrm{~nm}$, while the pass band begins at $1588 \mathrm{~nm}$ with a transmission of $85 \%$. This gives rise to an extinction in transmission of -3.9 $\mathrm{dB}$, a value worse than the one of $-15 \mathrm{~dB}$ reached by the same $\mathrm{PhC}$ etched into bulk LN. ${ }^{3}$ This is due to the combination of the roughness of the unpolished LN layer and the measurement technique. In fact, because of its nanometric roughness [Fig. 3(a)], the LN surface behaved like scattering centers that converted evanescent waves into propagating waves. This far field was detected by the dielectric probe and
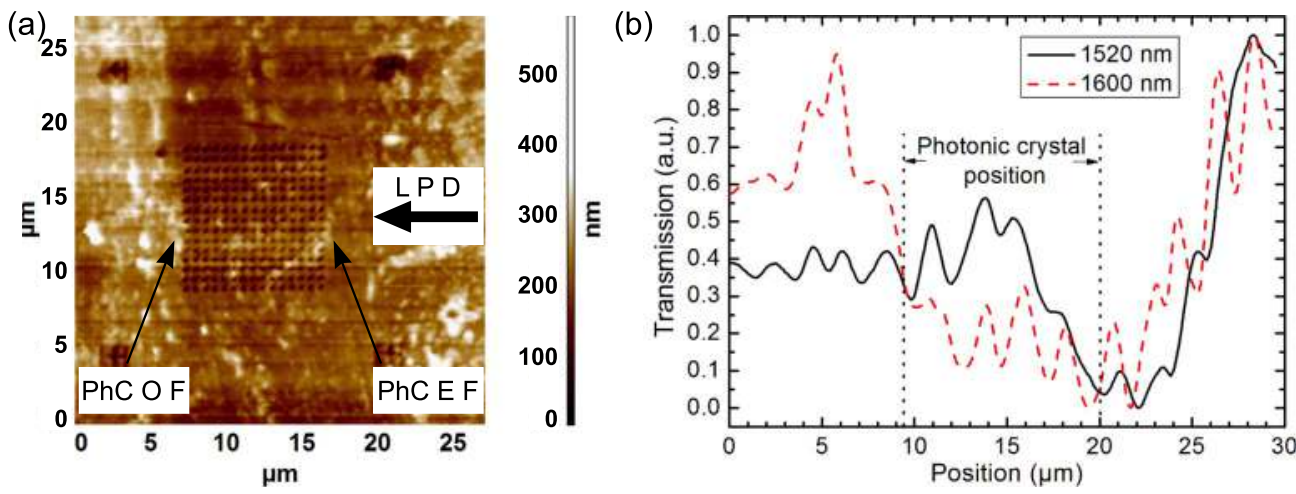

FIG. 3. (Color online) Examples of SNOM results. (a) Shear-force image of the LN PhC slab. PhCOF: PhC output face; PhCEF: PhC entrance face; LPD: light propagation direction. (b) Horizontal cross-section plotted at the center of the PhC above the optical near-field images acquired at 1520 and $1600 \mathrm{~nm}$, respectively. Notice that the light propagated from the right to the left. 


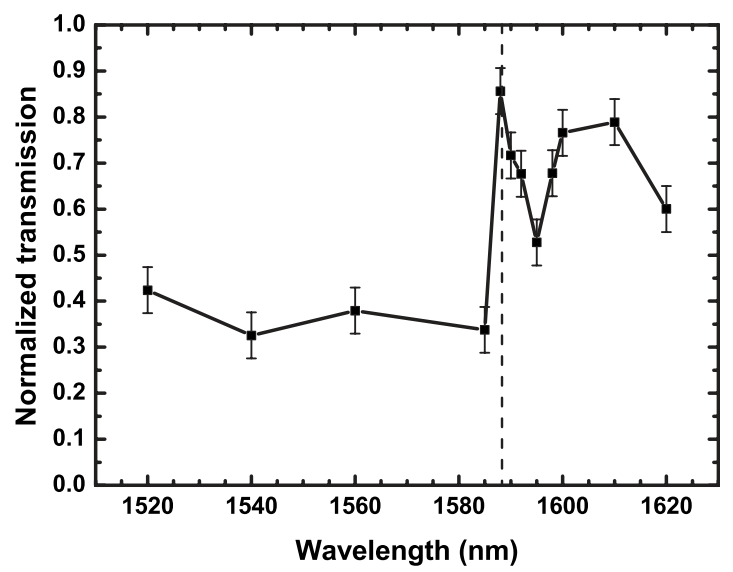

FIG. 4. Experimental transmission spectrum extracted from optical nearfield experiments. The vertical dashed line indicates the position of the stop band edge.

superimposed on the true optical near-field, increasing the background and degrading the extinction in transmission. Polishing the LN film would improve the extinction transmission. The most important result of this experiment lies in the much stronger sharpness of the upper band edge of the $\mathrm{PhC}$ etched into the slab waveguide. In fact, in this last case, only $3 \mathrm{~nm}$ are necessary to go from the forbidden to the allowed part of the transmission spectrum, while $300 \mathrm{~nm}$ were necessary for the $\mathrm{PhC}$ drilled into bulk $\mathrm{LN}^{3}$. The strong improvement in the spectral properties of the $\mathrm{PhC}$ is due to the verticality of the sidewalls of the holes etched into the LN thin film. ${ }^{7}$ This result is of great importance for active devices based on LN PhCs like those using LN electro-optics properties, since the applied voltage needed decreases as the slope of the band edge approaches $90^{\circ}$. As a consequence of the sharpness of the band edge, the Bragg oscillations missing in the transmission spectrum of the $\mathrm{PhC}$ etched into the bulk LN (Ref. 3) are measurable in the LN thin film. Those interference fringes, due to the multiple reflections of light between the two faces of the $\mathrm{PhC}$, are foreseen by 2D-FDTD simulations, as shown in Fig. 5.

The overall shape of the theoretical spectrum (Fig. 5) is reproduced in the experimental spectrum (Fig. 4). Some discrepancies between experiment and theory include the extinction in transmission that is lower for the experiment because of losses, and the position of the stop band edge. The experimental one is red shifted by $38 \mathrm{~nm}$ compared to the calculated one. This is due to the parameters used for the 2D-FDTD simulations. Reference 3 dealt with a PhC etched into an APE waveguide, so that $\mathrm{LN}$ with a refractive index of 2.143 was modeled. Calculations show that a red shift of the band edge of $38 \mathrm{~nm}$ corresponds to a material refractive index of 2.168. This value, bounded by the values of the extraordinary $\left(n_{e}\right)$ and the ordinary $\left(n_{o}\right)$ refractive indices of

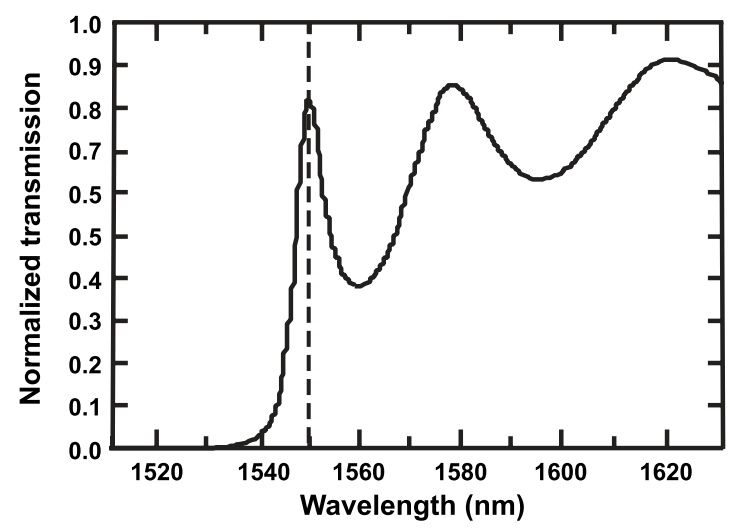

FIG. 5. Theoretical transmission spectrum of the PhC etched into a $\mathrm{LN}$ index gradient waveguide calculated by 2D-FDTD method. The position of the stop band edge is marked by the vertical dashed line.

$\mathrm{LN}\left(n_{e}=2.1373\right.$ and $n_{o}=2.2128$ at $\left.1.55 \mu \mathrm{m}\right)$ is in accordance with the fact that the LN thin film was polycrystalline.

In conclusion, we have demonstrated that the transmission properties of a $\mathrm{LN} \mathrm{PhC} \mathrm{can} \mathrm{be} \mathrm{improved} \mathrm{by} \mathrm{etching} \mathrm{it}$ into a thin film as opposed to an APE waveguide. This result, due to the almost vertical sidewall of the holes, is of great interest for the development of very efficient active devices based on $\mathrm{LN} \mathrm{PhCs}$ and using, for example, electro-optics properties of $\mathrm{LN}$, since the required tunable voltage will be lower in a thin film than the one expected in bulk LN. To benefit from such high efficiency, the LN thin layer should be characterized by single crystalline grains with a size at least equal to the PhC dimension $\left(\sim 100 \mu \mathrm{m}^{2}\right)$.

The authors are grateful to EU for its financial support under Grant No. STREP 033297 3D-DEMO.

${ }^{1}$ J. D. Joannopoulos, R. D. Meade, and J. N. Winn, Photonic Crystals: Molding the Flow of Light (Princeton University Press, Princeton, 1995).

${ }^{2}$ M. Roussey, M.-P. Bernal, N. Courjal, and F. I. Baida, Appl. Phys. Lett. 87, 241101 (2005).

${ }^{3}$ M. Roussey, M.-P. Bernal, N. Courjal, D. Van Labeke, and F. Baida, Appl. Phys. Lett. 89, 241110 (2006).

${ }^{4}$ M. Roussey, F. I. Baida, and M.-P. Bernal, J. Opt. Soc. Am. B 24, 1416 (2007)

${ }^{5}$ F. Lacour, N. Courjal, M.-P. Bernal, A. Sabac, C. Bainier, and M. Spajer, Opt. Mater. 27, 1421 (2005).

${ }^{6}$ J. Jackel, C. Rice, and J. Veselka, Appl. Phys. Lett. 41, 607 (1982).

${ }^{7}$ G. Burr, S. Diziain, and M.-P. Bernal, Opt. Express 16, 6302 (2008).

${ }^{8}$ M. Levy, J. R. M. Osgood, R. Liu, L. Cross, I. G. S. Cargill, A. Kumar, and H. Bakhru, Appl. Phys. Lett. 73, 2293 (1998).

${ }^{9}$ A. Guarino, G. Poberaj, D. Rezzonico, R. Degl'innocenti, and P. Günter, Nat. Photonics 1, 407 (2007).

${ }^{10}$ Y. Akiyama, K. Shitanaka, H. Murakami, Y.-S. Shin, M. Yoshida, and N. Imaishi, Thin Solid Films 515, 4975 (2007).

${ }^{11}$ Y. Kakehi, A. Okamoto, Y. Sakurai, Y. Nishikawa, T. Yotsuya, and S. Ogawa, Appl. Surf. Sci. 169, 560 (2001).

${ }^{12} n(\mathrm{MgO})=1.7$ at $1.55 \mu \mathrm{m} ; n_{e}(\mathrm{LN})=2.1373, n_{o}(\mathrm{LN})=2.2128$ at $1.55 \mu \mathrm{m}$ where the subscripts $e$ and $o$ are put for extraordinary and ordinary, respectively. 